\title{
Molecular Identification of Two Vegetative Compatibility Groups of Fusarium oxysporum f. sp. cepae
}

\author{
Michael J. Southwood, Altus Viljoen, Glaudina Mostert, and Adéle McLeod
}

Department of Plant Pathology, Stellenbosch University, Private Bag X1, Matieland, 7600, South Africa.

Accepted for publication 17 September 2011.

\begin{abstract}
Southwood, M. J., Viljoen, A., Mostert, G., and McLeod, A. 2012. Molecular identification of two vegetative compatibility groups of Fusarium oxysporum f. sp. cepae. Phytopathology 102:204-213.

Fusarium oxysporum f. sp. cepae, which causes basal rot of onion, consists of seven vegetative compatibility groups (VCGs 0420 to 0426) and several single-member VCGs (SMVs). F. oxysporum f. sp. cepae populations in South Africa and Colorado each consist of one main VCG (namely, VCG 0425 and 0421 , respectively). The aim of this study was to develop sequence-characterized amplified region (SCAR) markers for the identification of VCGs 0425 and 0421 , using 79 previously characterized F. oxysporum isolates. A second aim was to investigate the prevalence of VCG 0425 among 88 uncharacterized South African onion F. oxysporum isolates using (i) the developed SCAR markers and (ii) inter-retrotrans-

printing. Only two RAPD primers provided informative fingerprints for VCG 0425 isolates but these could not be developed into SCAR markers, although they provided diagnostic fragments for differentiation of VCG 0425 from VCG 0421. IR fingerprinting data were used to develop a multiplex IR-SCAR polymerase chain reaction method for the identification of VCG 0421, VCG 0425, and SMV 4 isolates as a group. Molecular identification of the uncharacterized collection of $88 \mathrm{~F}$. oxysporum isolates ( $65 \mathrm{~F}$. oxysporum f. sp. cepae and $23 \mathrm{~F}$. oxysporum isolates nonpathogenic to onion) confirmed that VCG 0425 is the main VCG in South Africa, with all but 3 of the 65 F. oxysporum f. sp. cepae isolates having the molecular characteristics of this VCG. Genotyping and VCG testing showed that two of the three aforementioned isolates were new SMVs (SMV 6 and SMV 7), whereas the third (previously known as SMV 3) now belongs to VGC 0247 .
\end{abstract} poson (IR)- and random amplified polymorphic DNA (RAPD) finger-
Fusarium oxysporum f. sp. cepae W. C. Snyder \& H. N. Hansen, which causes basal rot of onion, consists of seven known vegetative compatibility groups (VCGs 0420 to 0426) and several single-member VCGs (SMVs). VCG analyses of F. oxysporum $\mathrm{f}$. sp. cepae isolates have only been conducted for isolates collected in Japan, South Africa, Colorado (United States), and Turkey $(3,40,41)$. The first VCG analysis was conducted in Japan, where VCG 0420 was identified (45). In Colorado, four VCGs (VCGs 0421 to 0424) and SMV 4 were identified whereas, in South Africa two VCGs (VCGs 0425 and 0426) and three SMVs (SMVs 1 to 3 ) were identified. Among the $F$. oxysporum f. sp. cepae VCGs from Colorado and South Africa, two predominate: namely, VCG 0425 in South Africa (74\% of isolates) and VCG 0421 in Colorado (47\% of isolates) $(40,41)$. In contrast, in Turkey, 48 different $F$. oxysporum f. sp. cepae SMVs were identified that each consisted of a single isolate (3). Only VCG 0423 is shared between South Africa, Turkey, and Colorado but it does not predominate ( $<4 \%$ of isolates) in $F$. oxysporum $\mathrm{f}$. sp. cepae populations in South Africa and Turkey $(3,40)$. In Colorado, VCG 0423, although the second most abundant (26\%), was identified in only one eastern county, whereas VCG 0421 was widespread and occurred in the western and eastern counties of Colorado (41). Pathogenicity testing has shown that most VCG 0423 isolates are moderately virulent, whereas VCG 0421, VCG 0425, and SMV 4 isolates are highly virulent (40).

Due to the prevalence of VCGs 0421 and 0425 in South Africa and Colorado, and their high virulence, the rapid and accurate identification of these VCGs through molecular techniques is

Corresponding author. A. McLeod; E-mail address: adelem@sun.ac.za

http://dx.doi.org/10.1094/PHYTO-04-11-0107

(c) 2012 The American Phytopathological Society important. Translation elongation factor (EF) $1 \alpha$, mitochondrial small-subunit, and intergenic spacer (IGS) phylogenies revealed that VCGs 0421 and 0425 form a clonal lineage along with three SMVs (SMVs 2, 3, and 4), VCG 0426, and F. oxysporum isolates that are nonpathogenic to onion. Manual inspection of all the sequence data did not reveal any single-nucleotide polymorphisms that were unique to VCGs 0421 and 0425 (40). This is in contrast to studies on $F$. oxysporum f. sp. dianthi and f. sp. vasinfectum, where the IGS region was useful for discriminating pathogens from nonpathogens $(31,46)$. Furthermore, in $F$. oxysporum f. sp. cubense, the IGS region was useful for developing a polymerase chain reaction restriction fragment length polymorphism (PCRRFLP) method for distinguishing lineages within this pathogen (13).

DNA fingerprinting methods have been used with success for high-level resolution and identification of $F$. oxysporum at the forma specialis, race, and VCG levels. Two of the most widely used fingerprinting methods include amplified fragment length polymorphism (AFLP) analysis $(2,42)$ and random amplified polymorphic DNA (RAPD) analysis $(7,11,22,25,26,28,43)$. AFLP analyses have been used to distinguish between $F$. oxysporum $\mathrm{f}$. sp. melonis and f. sp. radicis-cucumerinum (42), to differentiate some VCGs of $F$. oxysporum f. sp. cubense (17), and to distinguish VCGs within a number of $F$. oxysporum formae speciales causing wilt and rot diseases (2). RAPD analyses have been used to identify, for example, highly virulent strains of $F$. oxysporum $\mathrm{f}$. sp. ciceris and $\mathrm{f}$. sp. phaseoli $(1,25)$ and distinguish between races of $F$. oxysporum f. sp. pisi and f. sp. ciceris $(16,22,33)$ and between VCGs of $F$. oxysporum $\mathrm{f}$. sp. cubense and $\mathrm{f}$. sp. dianthi $(4,24)$.

A new fingerprinting method for differentiating $F$. oxysporum $\mathrm{f}$. sp. lactucae race 1 isolates targets transposons and is a sequencebiased method. This method, known as inter-retrotransposon amplified polymorphism (IRAP)-PCR, targets the long terminal 
repeat (LTR) insertion sites of transposons and, therefore, amplifies genomic regions between LTRs (35). It is better to target the LTR insertion sites than transposons, because these sites are more conserved, and transposition events do not influence their position in the genome, as can be the case with transposons $(19,30,38)$.

Several studies have used DNA fingerprinting data to develop sequence-characterized amplified region (SCAR) markers for the rapid and accurate identification of formae speciales, races, or VCGs of $F$. oxysporum. SCAR makers provide a simple and costeffective way of identifying these groups, which can be used interlaboratorially (30). The latter is important because RAPD analysis, especially, suffers from a lack of interlaboratory reproducibility, and sometimes also from intralaboratory variability (23). RAPD analysis remains an important approach for developing SCAR markers for high-resolution identification of $F$. oxysporum groups, because $64 \%$ (14 of 22) of all SCAR markers that have been developed have used this approach. The remaining SCAR markers (36\%) were developed using either the IRAP-PCR approach or various molecular approaches that targeted transposable elements (30).

The aims of this study were, first, to develop DNA fingerprinting methods for identifying the two $F$. oxysporum f. sp. cepae VCGs (VCGs 0421 and 0425) using a collection of 79 previously characterized $F$. oxysporum isolates obtained from onion. Second, the fingerprint data were used to develop SCAR markers for the identification of VCG 0421, VCG 0425, and SMV 4 isolates among the South African and Colorado F. oxysporum f. sp. cepae isolates. Finally, the fingerprint methods and SCAR markers, along with pathogenicity testing, were used to investigate the prevalence of VCG 0425 among 88 uncharacterized $F$. oxysporum isolates from onion bulbs in South Africa. To validate the ability of the markers to identify VCGs 0421 and 0425, a blind trial was performed in which a number of previously uncharacterized isolates from onion were subjected to parallel molecular and VCG analyses. The results were contrasted to assess accuracy of the molecular method.

\section{MATERIALS AND METHODS}

Fungal isolates. In total, 186 Fusarium isolates were used in the study, which included 79 previously characterized $F$. oxysporum isolated from onion (Table 1, groups 1 and 3). Isolates were grown routinely on potato dextrose agar (PDA) (Biolab, Gauteng, South Africa) supplemented with $0.04 \mathrm{~g}$ of streptomycin sulfate per liter of agar $\left(\mathrm{PDA}^{+}\right)$. All isolates were stored in $15 \%$ glycerol at $-80^{\circ} \mathrm{C}$.

DNA extraction. Fusarium mycelia were harvested from 2-week-old $\mathrm{PDA}^{+}$plates. DNA was extracted with the Wizard SV Genomic DNA Purification system (Promega Corporation, Madison, WI) according to the manufacturer's protocol, except that mycelia were first lysed using $0.5 \mathrm{~g}$ of glass beads $(2 \mathrm{~mm}$ in diameter) and 5 min of shaking on a Mixer Mill type MM 301 beater (Retsch $\mathrm{GmbH} \& \mathrm{Co}$. KG, Haan, Germany). DNA was eluted from the columns using $100 \mu \mathrm{l}$ of sterile distilled water. DNA concentrations were determined using a NanoDrop-1000 (NanoDrop Technologies, Inc., DE).

Two independent DNA extractions were made from $82 \mathrm{Fu}$ sarium isolates (Table 1, groups 1 to 3 ). These independent DNA extractions consisted of $F$. oxysporum culture plates that were grown at two different points in time. The duplicated DNA extractions were used to evaluate the reproducibility of the RAPD and IRAP-PCR analyses.

RAPD fingerprinting. Twenty RAPD primers were evaluated that had previously been used for characterizing isolates of other formae speciales of $F$. oxysporum. The RAPD primers were OPF06, OPF-10, OPF-12, OPI-01, OPI-09, and OPI-18 (22); OPC-18 (1); OPF-04, OPF-05, OPF-08, and OPF-13 (14); OPB-01 and OPB-02 (42); OPB-08 (6); OPA-01, OPA-02, OPA-04, and OPA05 (7); and OPB-07 and OPZ-12 (28). The primers were evalu-

TABLE 1. Fusarium isolates used in the study

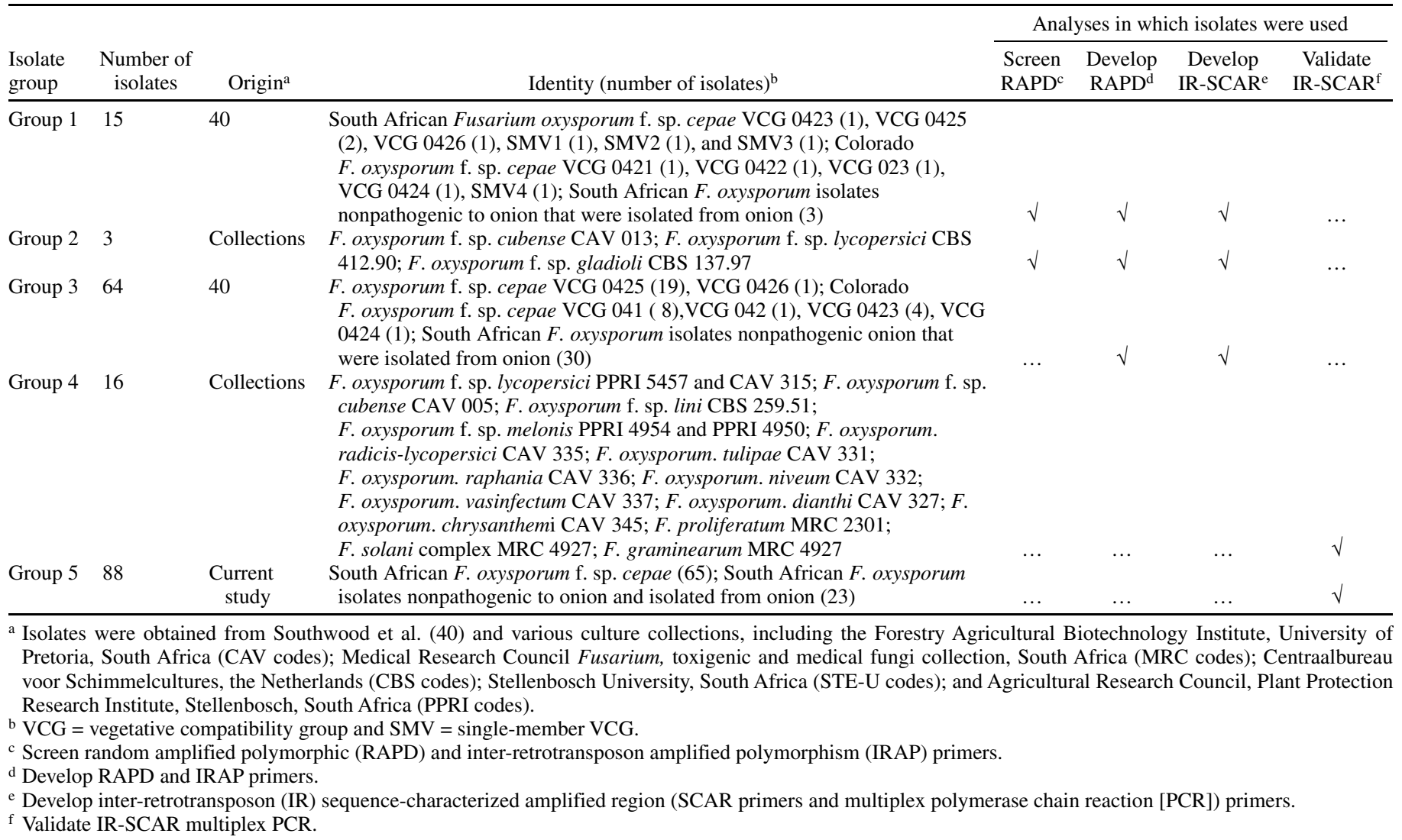


ated for their ability to generate polymorphic fingerprinting patterns and to differentiate between the main VCGs (VCGs 0421 and 0425), SMVs, and nonpathogenic $F$. oxysporum isolates using a subset of 18 Fusarium isolates (Table 1, groups 1 and 2).

All RAPD amplifications were conducted using AmpliTaq DNA polymerase Stoffel fragment (Applied Biosystems, Foster City, CA) to increase the reproducibility of RAPD amplifications. The AmpliTaq DNA polymerase Stoffel fragment is highly thermostable and exhibits optimal activity over a broad range of magnesium ion concentrations. The enzyme also has a deletion of 289 amino acids at the $\mathrm{N}$ terminal that results in increased stringency at lower ionic strengths and reduced misextensions (Applied Biosystems). Each RAPD amplification reaction consisted of $26 \mathrm{ng}$ of genomic DNA, $1 \mu \mathrm{M}$ RAPD primer (Operon Biotechnologies GmbH, Cologne, Germany), $400 \mu \mathrm{M}$ each dNTP, bovine serum albumin (BSA) Fraction V (Roche Diagnostics, Randburg, South Africa) at $0.104 \mathrm{mg} / \mathrm{ml}$, 1× Stoffel buffer (Applied Biosystems), $3 \mathrm{mM} \mathrm{MgCl}$, and $1 \mathrm{U}$ of AmpliTaq DNA polymerase Stoffel fragment (Applied Biosystems) in a total volume of $25 \mu \mathrm{l}$. Amplifications were performed in an Applied Biosystems 2720 Thermal Cyclerprogrammed for 1 cycle of $5 \mathrm{~min}$ at $95^{\circ} \mathrm{C}$ followed by 44 cycles of $1 \mathrm{~min}$ at $95^{\circ} \mathrm{C}, 1 \mathrm{~min}$ at $35^{\circ} \mathrm{C}, 2 \mathrm{~min}$ at $72^{\circ} \mathrm{C}$, and a final extension step of $6 \mathrm{~min}$ at $72^{\circ} \mathrm{C}$. Amplification products were separated by electrophoresis on a 3\% agarose gel (MS-8 agarose, molecular screen; Hispanagar, Burgos, Spain) containing ethidium bromide and visualized under UV light.

Two RAPD primers (OPA-05 [5'-AGGGGTCTTG] and OPI-18 [5'-TGCCCAGCCT]) were used to generate RAPD fingerprints for the 82 Fusarium isolates (Table 1, groups 1 to 3). These RAPD primers were the only 2 of the 20 evaluated RAPD primers that yielded fragments that were diagnostic for VCG 0425 isolates. RAPD reactions, amplifications, and gel electrophoresis were conducted as described above. For each isolate, two amplifications were conducted from two independent DNA extractions in order to check for reproducibility.

IRAP-PCR fingerprinting. Four published LTR primers (Hani, Gagi, Hana, and Gaga) (35) were evaluated. The four primers were screened in all possible combinations on a subset of 18 Fusarium isolates (Table 1, groups 1 and 2) in order to identify the primer pair combinations that showed the best potential for revealing fingerprinting patterns and fragments that were correlated with $F$. oxysporum f. sp. cepae VCGs 0421 and 0425.

Each IRAP-PCR reaction consisted of $100 \mathrm{ng}$ of genomic DNA, $0.40 \mu \mathrm{M}$ each of two LTR primers, $500 \mu \mathrm{M}$ of each dNTP, $1 \times$ AccuTaq LA Buffer (Sigma-Aldrich, Kempton Park, South Africa), $1.5 \mathrm{mM} \mathrm{MgCl}, 1 \mu \mathrm{l}$ of dimethyl sulfoxide (supplied with AccuTaq), and $1 \mathrm{U}$ of AccuTaq LA DNA Polymerase (SigmaAldrich) in a total volume of $30 \mu \mathrm{l}$. Amplifications were performed in an Applied Biosystems 2720 Thermal Cycler programmed for 1 cycle of $30 \mathrm{~s}$ at $98^{\circ} \mathrm{C} ; 40$ cycles of $15 \mathrm{~s}$ at $94^{\circ} \mathrm{C}$, $20 \mathrm{~s}$ at $55^{\circ} \mathrm{C}$, and $5 \mathrm{~min}$ at $68^{\circ} \mathrm{C}$; followed by 1 cycle of $10 \mathrm{~min}$ at $68^{\circ} \mathrm{C}$. Amplification products were separated by electrophoresis on a $2 \%$ agarose gel (MS-8 agarose) stained with ethidium bromide, and visualized under UV light.

One LTR primer pair, Hani (5'-GAACCCTCCAACATT CAACA-3') and Gagi (5'-TAACCGCTAGGGTCGTAACA-3') (35), was used to generate IRAP-PCR fingerprints for the 82 Fusarium isolates (Table 1, groups 1 to 3 ). This primer pair combination was the only combination that was able to differentiate VCG 0421, VCG 0425, and SMV 4 isolates from all the other VCGs, SMVs, and F. oxysporum isolates nonpathogenic to onion. IRAP-PCR reactions, amplifications, and gel electrophoresis were conducted as described above. Amplification of each isolate was conducted twice, in order to confirm the reproducibility of the technique.

Cloning and sequencing of RAPD and IRAP-PCR fragments. The RAPD and IRAP fragments that were correlated with
VCGs 0421 and 0425 were cloned and sequenced from four South African F. oxysporum f. sp. cepae isolates (STE-U 6649, 6640, 6643, and 6656). Cloning of the PCR fragments was conducted by first excising each targeted PCR fragment from a 3\% (RAPD fragments) or $2 \%$ (IRAP fragments) agarose gel. The gelexcised fragments were purified using the QIAquick Gel Extraction kit (Qiagen, Venlo, Valencia, CA). The purified fragments were ligated into vector pJET1.2 using the CloneJet PCR cloning kit (Fermentas International Inc., Ontario, Canada). The ligated plasmids were transformed into competent Escherichia coli cells using a standard protocol (39). E. coli colonies containing inserts of the correct size were selected using PCR colony screening with forward and reverse pJET1.2 primers (Fermentas International Inc.). Plasmids were extracted from colonies that yielded the correct-sized PCR fragment using the PureYield Plasmid miniprep system (Promega Corporation). The cloned fragments were sequenced from the plasmids using the pJET1.2 primers. For each of the four isolates, one to two cloned fragments were sequenced. Sequence analyses were conducted by the Central Analytical Sequencing Facility at Stellenbosch University using the BigDye system (version 3.1 dye terminators; Applied Biosystems) and an ABI 3130XL Genetic Analyzer. Geneious Pro (Biomatters Ltd., Auckland, New Zealand) was used to view ABI trace files and to obtain consensus double-strand sequences for each cloned fragment. Sequence data was submitted to GenBank (http://www. ncbi.nlm.nih.gov/Genbank/) as accessions GU120664 to GU120669. The identities of the cloned fragments were investigated by conducting analyses in the BLASTN and BLASTX programs of the National Center for Biotechnology Information (NCBI) network services and the Fusarium comparative genome project at the Broad Institute (http://www.broadinstitute.org/ annotation/genome/fusarium_group/MultiHome.html).

Design and evaluation of SCAR primers. SCAR primers were designed by selecting sequence regions within the cloned RAPD and IRAP fragments that were $100 \%$ identical among the sequences of the four isolates used in the cloning experiments. The sequence of each of the designed primers was also analyzed for specificity (amplification of other known sequences in GenBank and the Fusarium genome database), melting temperature, self-homology, cross-homology, internal stability, and compatibility with a complimentary primer using the NCBI PrimerBLAST website (http://www.ncbi.nlm.nih.gov/tools/primer-blast).

In total, 17 SCAR primers were designed from the cloned RAPD and IRAP fragments (Table 2). The specificity of the primer pair combinations was tested using genomic DNA from a small subset of isolates, including four South African VCG 0425 isolates (STE-U 6641, 6657, 6660, and 6661), three Colorado VCG 0421 isolates (Foc 1, Foc 4, and Foc 8), one Colorado VCG 0424 isolate (Foc 23), four $F$. oxysporum isolates nonpathogenic to onion (STE-U 6664, 6665, 6666, and 6676), and one F. oxysporum f. sp. lycopersici isolate (PPRI 5457). The PCR reactions were optimized using different primer and $\mathrm{MgCl}_{2}$ concentrations and annealing temperatures. It was found that the SCAR primers designed from the two RAPD sequences were not specific. However, three of the inter-retrotransposon (IR)-SCAR primer pairs were specific when tested on the subset of isolates. These primer pairs were (i) HanO- $1 \mathrm{~F}$ and $\mathrm{HanO}-2 \mathrm{R}$ that amplifies a 359-bp fragment, (ii) Hansec- $1 \mathrm{~F}$ and Hansec-2R that amplifies a 392-bp fragment, and (iii) HTH-1F and HTH-2R that amplifies a 244-bp fragment.

The three IR-SCAR primer pairs were evaluated on $82 \mathrm{Fu}$ sarium isolates (Table 1, groups 1 to 3 ). The PCR reactions were carried out using 30- $\mu$ l reaction volumes containing $20 \mathrm{ng}$ of genomic DNA, $200 \mu \mathrm{M}$ each dNTP, BSA Fraction V (Roche Diagnostics) at $1 \mathrm{mg} / \mathrm{ml}, 1 \times$ PCR buffer, $1.5 \mathrm{mM} \mathrm{MgCl}_{2}, 0.65 \mathrm{U}$ of BIOTAQ (Bioline, London), and $1 \mu \mathrm{M}$ each HanO-1F and HanO-1R primer, $0.5 \mu \mathrm{M}$ each HTH-1F and HTH-2R primer, or $0.2 \mu \mathrm{M}$ each Hansec-1F and Hansec-2R primer. Thermal cycling 
conditions comprised an initial denaturation at $94^{\circ} \mathrm{C}$ for $5 \mathrm{~min}$; followed by 40 cycles of denaturation at $94^{\circ} \mathrm{C}$ for $30 \mathrm{~s}$, annealing at $60^{\circ} \mathrm{C}$ for $30 \mathrm{~s}$, and elongation at $72^{\circ} \mathrm{C}$ for $30 \mathrm{~s}$; and a final elongation step at $72^{\circ} \mathrm{C}$ for $7 \mathrm{~min}$. Amplifications were performed in an Applied Biosystems 2720 Thermal Cycler. The amplified products $(5 \mu \mathrm{l}$ each) were electrophoretically resolved on a $3 \%$ agarose gel (MS-8 agarose) stained with ethidium bromide, and visualized under UV light.

Development of IR-SCAR multiplex PCRs. To increase the reliability of our IR-SCAR markers for identifying the correct VCGs, we developed a multiplex IR-SCAR PCR test that targets more than one genome region. Two IR-SCAR multiplex PCR reactions were evaluated for detecting all VCG 0421, VCG 0425, and SMV 4 isolates in a single reaction. The first IR-SCAR multiplex PCR reaction consisted of amplifications conducted with primers HanO-1F, HanO-2R, HTH-1F, and HTH-2R. The second IR-SCAR multiplex PCR reaction consisted of amplifications conducted with primers Hansec-1F, Hansec-2R, HTH-1F, and HTH-2R. These two multiplex reactions were tested on a subset of 18 Fusarium isolates (Table 1, groups 1 and 2) and two F. oxysporum f. sp. melonis isolates (from group 4 isolates) (Table 1). Several different reaction conditions $\left(\mathrm{MgCl}_{2}\right.$ and primer concentrations) and amplification conditions (annealing temperatures) were evaluated. Only the primers Hansec-1F, Hansec-2R, HTH-1F, and HTH-2R were specific enough to identify VCGs.

The IR-SCAR multiplex PCR amplifications using primers Hansec-1F, Hansec-2R, HTH-1F, and HTH-2R were conducted on $64 \mathrm{~F}$. oxysporum isolates (group 3) (Table 1). The IR-SCAR multiplex reaction consisted of $20 \mathrm{ng}$ of genomic fungal DNA, $200 \mu \mathrm{M}$ each dNTP, BSA Fraction V (Roche Diagnostics) at $1 \mathrm{mg} / \mathrm{ml}, 1 \times$ PCR buffer, $1.5 \mathrm{mM} \mathrm{MgCl}_{2}, 0.65$ unit BIOTAQ (Bioline), $0.2 \mu \mathrm{M}$ each Hansec-1F and Hansec-2R primer, and $0.5 \mu \mathrm{M}$ each HTH-1F and HTH-2R primer in a total volume of $30 \mu \mathrm{l}$. Thermal cycling conditions comprised an initial denaturation at $94^{\circ} \mathrm{C}$ for $5 \mathrm{~min}$; followed by 36 cycles of denaturation at $94^{\circ} \mathrm{C}$ for $30 \mathrm{~s}$, annealing at $60^{\circ} \mathrm{C}$ for $30 \mathrm{~s}$, and elongation at $72^{\circ} \mathrm{C}$ for $30 \mathrm{~s}$; and a final elongation step at $72^{\circ} \mathrm{C}$ for $7 \mathrm{~min}$. Amplifications were performed in an Applied Biosystems 2720 Thermal Cycler. The amplified products $(8 \mu \mathrm{l})$ were electrophoretically resolved on a $3 \%$ agarose gel (MS- 8 agarose) stained with ethidium bromide and visualized under UV light.

Isolation, identification, and pathogenicity testing of a new collection of $F$. oxysporum isolates from onion bulbs in South Africa. Fusarium isolations were made from onion bulbs col- lected in the Koue Bokkeveld in 2007 and in the Boland in 2005 directly after harvest. Fusarium isolates were isolated from mature onion bulbs by first removing the outer two fleshy bulb scales and 3 to $5 \mathrm{~mm}$ of the outer basal plate tissue. Subsequently, small tissue pieces ( 1 to $3 \mathrm{~mm}$ in diameter) were taken from the basal plate and placed onto $\mathrm{PDA}^{+}$plates. Plates were incubated at $25 \pm 4^{\circ} \mathrm{C}$ on the laboratory and inspected regularly for fungal growth. All isolates were hyphal tipped, followed by single-spore isolation. All Fusarium isolates were identified to the species level using conidial morphology as described by Leslie and Summerell (27). The morphological identifications were supported by sequence identification using the translation EF as described by Baayen et al. (2). All $F$. oxysporum isolates were single spored and stored in $15 \%$ glycerol at $-80^{\circ} \mathrm{C}$. In total, $88 \mathrm{~F}$. oxysporum single-spored isolates were obtained that were deposited in the fungal culture collection at Stellenbosch University, Department of Plant Pathology as STE-U 6847 to 6934.

The pathogenicity of the 88 newly isolated $F$. oxysporum isolates was evaluated using a basal plate inoculation method of mature onion bulbs, as previously described (40). Briefly, for each isolate, a spore concentration of $5 \times 10^{4}$ conidia/ml was used to inoculate the basal plate of onion bulbs that were wounded using a sterile scalpel ( $\approx 20$ shallow, 5 -mm wounds per plate). The bulbs were incubated in brown paper bags in moisture chambers for 6 weeks, after which $5 \mathrm{~mm}$ of the outer basal plate was cut off and the percentage necrosis was evaluated on the cut basal plate section. Isolates were designated as highly virulent when they caused 70 to $100 \%$ necrosis of the basal plate section in four inoculated bulbs in two repeat experiments. Isolates that caused 0 to $10 \%$ necrosis were designated nonpathogenic because pathogenicity was detected through necrosis, which developed inconsistently where wounds were created for the purpose of inoculation (40). Pathogenicity testing of each isolate was conducted using four onion bulbs, as well as negative control isolates consisting of two isolates representing other $F$. oxysporum formae speciales ( $F$. oxysporum f. sp. cubense and f. sp. lycopersici), an $F$. oxysporum isolate nonpathogenic to onion that was isolated from onion, and a water control. These isolates were all included as negative controls to ensure that the symptoms that developed were due to the pathogenic nature of the isolates and not to secondary infection of the wounds that were made during the inoculation process. Two known $F$. oxysporum f. sp. cepae isolates were also included in the assays to ensure that environmental conditions were suitable for infection and symptom expression.

TABLE 2. Sequence-characterized amplified region (SCAR) primers designed for amplification of Fusarium oxysporum f. sp. cepae vegetative compatibility groups (VCGs) 0421 and 0425

\begin{tabular}{|c|c|c|}
\hline Fragment $^{\mathrm{a}}$ & SCAR primer name ${ }^{b}$ & SCAR primer sequence \\
\hline \multirow[t]{2}{*}{ RAPD OPA-05 fragment (402 bp) } & OPA-1F & 5'-CTTGCCATGACAGGGCTC-3' \\
\hline & OPA- $2 \mathrm{~F}$ & $5^{\prime}$-TGGACATGTACCACAGAAAGC-3' \\
\hline \multirow{2}{*}{ RAPD OPI-18 fragment (371-374 bp) } & $\mathrm{OPI}-2 \mathrm{~F}$ & 5'-CAGCCTAGAGGGGTTTTGCT-3' \\
\hline & OPI-1R & 5'-ATTCTGGATCCAATGAAGCG-3' \\
\hline IRAP-One fragment (1.35 kb) & $\mathrm{HanO}-1 \mathrm{~F} \dagger$ & 5'-GAACCCТCCАACATTCAACAC-3' \\
\hline \multirow[t]{3}{*}{ IRAP-Two fragment (783 bp) } & Hansec-1F* & 5'-TTATTGCCCTCATCGGAAAG-3' \\
\hline & Hansec-1R & 5'-АСССТССААСАТТСААСАGC-3' \\
\hline & Hansec-2R* & 5'-ACCAGCATGCAGCAACAGTC-3' \\
\hline \multirow{4}{*}{ IRAP-Three fragment (406 bp) } & HTH-1F* & 5'-CATCGGAAGTGACATGGTTG-3' \\
\hline & HTH-2F & 5'-TAACCGCTAGGGTCGTAACA-3' \\
\hline & HTH-1R & 5'-TCTCTGCCAGTTCGGAGATT-3' \\
\hline & HTH-2R* & 5'-AGGCTTTTCCAGCATTTGAA-3' \\
\hline
\end{tabular}

\footnotetext{
${ }^{a}$ Random amplified polymorphic DNA (RAPD) or inter-retrotransposon amplified polymorphism (IRAP) fragments were used to design the SCAR primers.

${ }^{b}$ Primer names followed by an asterisk $\left(^{*}\right)$ were used in the IR-SCAR multiplex polymerase chain reaction that identifies VCG 0421 , VCG 0425 , and singlemember VCG (SMV) 4 as a group, and those followed by $\dagger$ were associated with F. oxysporum f. sp. cepae VGC 0421, VCG 0425 , and SMV. None of the other primers were associated with specific VCGs.
} 
When basal plate necrosis did occur, the pathogen was reisolated from the basal plate onto $\mathrm{PDA}^{+}$to fulfill Koch's postulates.

RAPD and IRAP-PCR fingerprinting of the new collection of $\boldsymbol{F}$. oxysporum isolates from South Africa. RAPD primers OPA-05 and OPI-18 and IRAP-PCR primer pair Hani and Gagi were used to generate fingerprints for the new collection of $88 \mathrm{~F}$. oxysporum isolates (Table 1, group 5) from onion, using the same protocols as described above. Amplifications were only conducted using one DNA extraction, because fingerprints generated from independent DNA extractions were found to be reproducible. The RAPD OPA-05 and OPI-18 fingerprints of the 88 isolates were scored for the presence or absence of a \pm 400 and \pm 370 -bp diagnostic VCG 0425 fragments, respectively (Fig. 1). The IRAP fingerprint of each of the 88 isolates was also scored for the presence or absence of three diagnostic fragments $( \pm 400-b p$, \pm 780 -bp, and \pm 1.35 -kb) (Fig. 2).

Validation of the IR-SCAR multiplex PCR. The IR-SCAR multiplex PCR (primers Hansec-1F, Hansec-2R, HTH-1F, and HTH-2R) was further validated on a total of 104 Fusarium isolates (Table 1, groups 4 and 5). The IR-SCAR multiplex reaction and amplification conditions were conducted as described above.
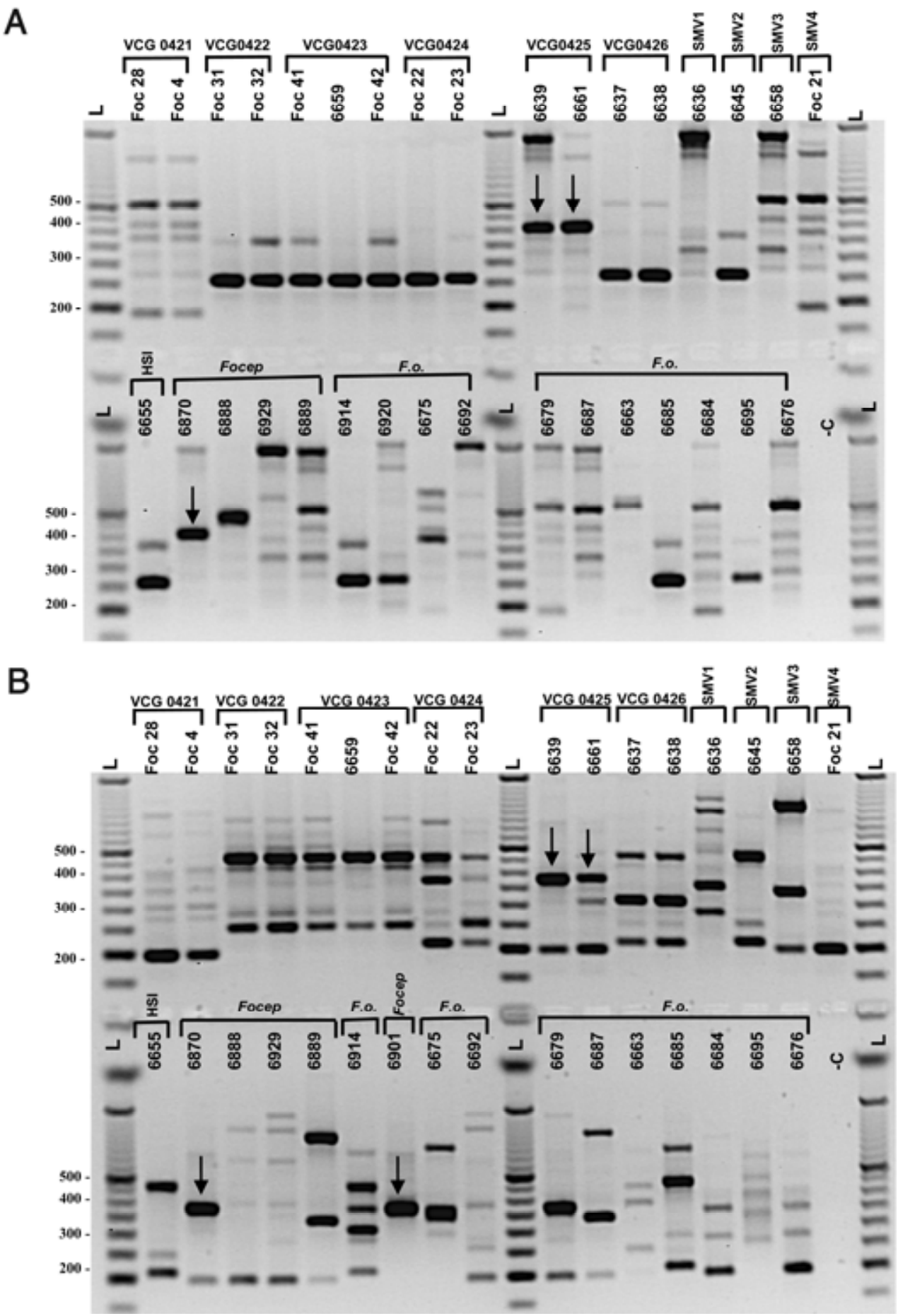

Fig. 1. Random amplified polymorphic DNA (RAPD) fingerprints obtained for onion Fusarium oxysporum isolates with RAPD primers A, OPA-05 and B, OPI18. Codes for F. oxysporum f. sp. cepae isolates from Colorado start with "Foc", whereas the South African pathogenic and nonpathogenic ( $F$. oxysporum) isolates are indicated by numbers that represent their STE-U culture collection codes. VCGs = vegetative compatibility groups, SMVs $=$ single-member VCGs, and HSI = heterokaryon self-incompatible isolates. Diagnostic amplicons for VCG 0425 isolates are indicated by arrows. Size fragments (bp) of a 50-bp Generuler ladder (L) are indicated on the left side of the figure. A negative water control $(-\mathrm{C})$ was included in amplifications. 
Vegetative compatibility tests. The VCG status of a subset of 14 isolates from the new collection of $88 \mathrm{~F}$. oxysporum isolates (Table 1) from onion was determined, to confirm the molecular identification with SCAR markers. The isolates included four isolates that were identified as VCG 0425 (STE-U 6847, 6873, 6880, and 6862), six nonpathogenic isolates (STE-U 6915, 6922, 6918, 6912, 6913, 6916, and 6915), and three F. oxysporum f. sp. cepae isolates that, based on molecular data, did not belong to VCG 0421 (STE-U 6889, 6888, and 6929). VCG determination was done using standard techniques as previously described $(37,41)$. Nitrate-nonutilizing (nit) mutants were generated as spontaneous chlorate-resistant sectors on minimal medium containing $4 \%$ chlorate $\left(\mathrm{ClO}_{3}^{-}\right)$. The chlorate concentration was altered for all of the isolates for which nit mutants failed to generate. For all the isolates, heterokaryon self compatibility was first determined by pairing different nitl and NitM mutants of the same isolate with each other. Subsequently, the nit mutant isolates of unknown VGC identity were paired against nit mutants of isolates representing the known VCG groups of $F$. oxysporum $\mathrm{f}$. sp. cepae $(37,41)$. A line of robust mycelial growth between complementary nit mutants indicated the VCG identity of the isolate. For all the isolates used in the vegetative compatibility tests, heterokaryon self compatibility was first determined by pairing different nitl and NitM mutants of the same isolate. Subsequently, the NitM mutants of 12 isolates that represented the known F. oxysporum f. sp. cepae VCGs (VCGs 0421 to 0426) and SMVs (SMVs 1 to 4) were tested for stable heterokaryon formation when paired with the nitl mutants of the $13 \mathrm{~F}$. oxysporum isolates from the new collection, or vice versa.

\section{RESULTS}

RAPD fingerprinting. Amplification of the 82 Fusarium isolates (Table 1, groups 1 to 3 ) with RAPD primer OPA-05 yielded one to seven PCR fragments. For amplifications with RAPD primer OPI-18, 1 to 13 PCR fragments were obtained. Amplification with RAPD primers OPI-18 and OPA-05 further each revealed a \pm 370 and 400-bp fragment, respectively, which were only associated with VCG 0425 isolates (Fig. 1).

IRAP-PCR fingerprinting. Amplification of the $82 F$. oxysporum isolates with primer pair Hani and Gagi yielded 0 to 13 PCR fragments. Three fragment sizes of $\approx 400 \mathrm{bp}, 780 \mathrm{bp}$, and $1.35 \mathrm{~kb}$ were present in all VCG 0421 and VCG 0425 isolates. The SMV 4 isolate only contained the \pm 400 -bp and $\pm 1.35-\mathrm{kb}$ fragments. These diagnostic bands were absent from the other $F$. oxysporum f. sp. cepae VCGs and SMVs and from F. oxysporum isolates nonpathogenic to onion (Fig. 2).

Cloning and sequencing of RAPD and IRAP-PCR fragments. The sequences obtained from the IRAP \pm 400 -bp, \pm 780 -bp, and \pm 1.35 -kb fragments will hereafter be referred to as IRAP-

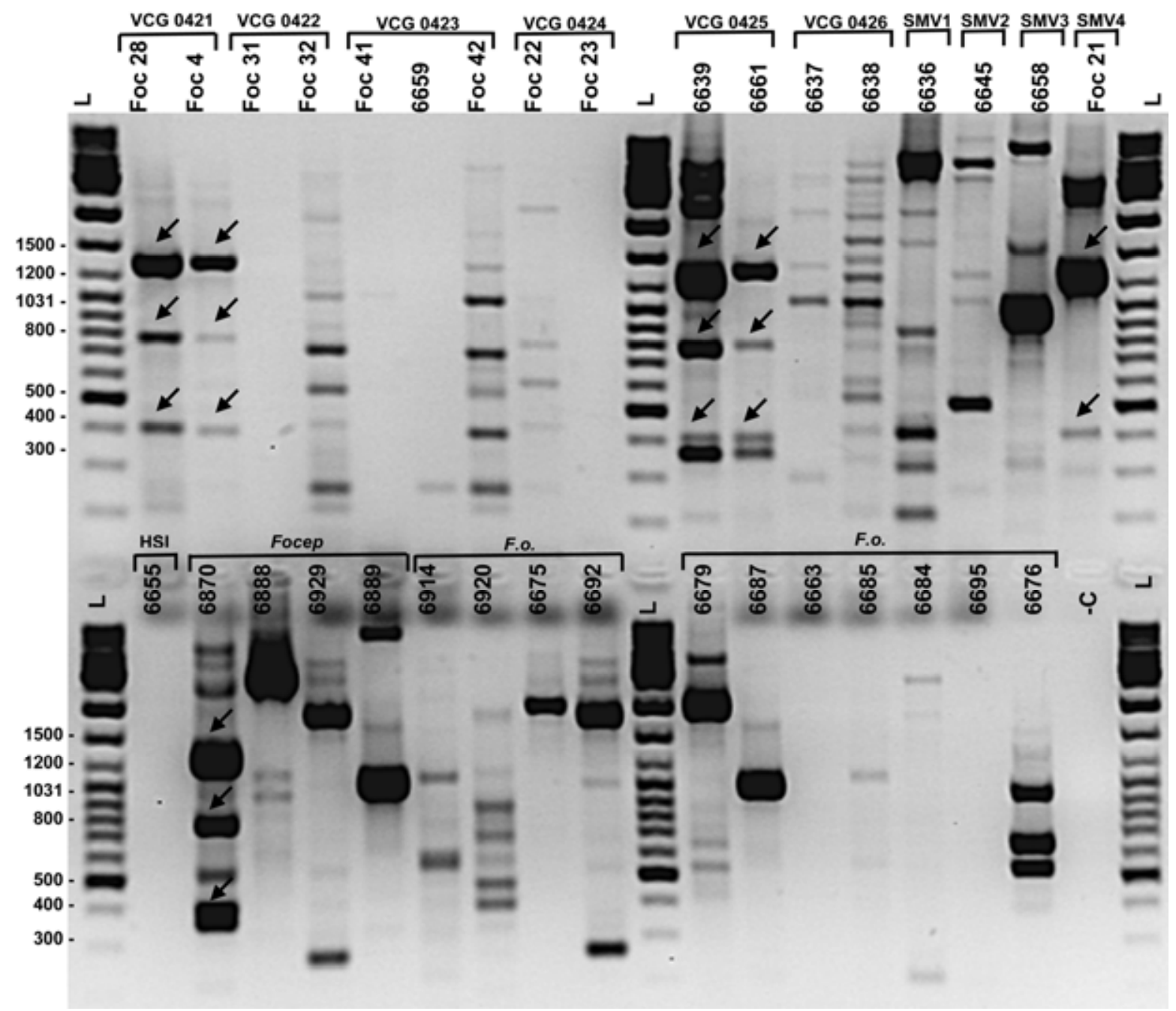

Fig. 2. Inter-retrotransposon amplified polymorphism (IRAP) fingerprints obtained with primers Hani and Gagi for Fusarium oxysporum isolates from onion. Codes for F. oxysporum f. sp. cepae isolates from Colorado start with "Foc", whereas the South African pathogenic and nonpathogenic (F. oxysporum) isolates are indicated by numbers that are their STE-U culture collection codes. VCGs = vegetative compatibility groups, SMVs = single-member VCGs, and HSI = heterokaryon self-incompatible isolates. Three diagnostic amplicons for VCG 0421 and VCG 0425 isolates are indicated by arrows. Size fragments (bp) of a 100-bp Generuler ladder (L) are indicated on the left side of the figure. A negative water control (-C) was also included in amplifications. 
Three, IRAP-Two, and IRAP-One sequences, respectively. The RAPD \pm 400 -bp OPA-05 fragment will be referred to as the OPA05 sequence, and the two polymorphic OPI-18 \pm 370 -bp fragments (see below) as the OPI-18A and OPI-18B sequences.

The sequences (GenBank accessions GU120664 to GU120669) of the cloned RAPD and IRAP fragments from the four South African $F$. oxysporum f. sp. cepae isolates were sometimes not identical. The OPA-05 (GU120664), IRAP-One (GU120667), IRAP-Two (GU120668), and IRAP-Three (GU120669) sequences were similar. However, the OPI-18 sequence obtained from isolate STE-U 6649 (GU120666) differed from the sequences (GU120665) of the other three isolates (all VCG 0425 isolates) by having 13 single base pair polymorphisms and 3 single base pair deletions that were distributed across the length of the sequence (Table 3).

Some of the cloned $F$. oxysporum f. sp. cepae sequences were similar to sequences in GenBank or the Fusarium comparative genome project ( $F$. verticillioides, $F$. oxysporum, and $F$. graminearum genomes) at the Broad Institute. These included the IRAP-One, IRAP-Two, and OPA-05 sequences. No significant matches, however, were found for the IRAP-Three, OPI-18A, and OPI-18B sequences in GenBank (BLASTN and BLASTX) or the Fusarium comparative genome project databases (Table 3 ).

The IRAP-One sequence $(1.348 \mathrm{~kb})$ contained a 297-bp region (positions 21 to $318 \mathrm{bp}$ ) and a 464-bp region (positions 810 to $1,274 \mathrm{bp}$ ) that had a 96 to $98 \%$ similarity to GenBank sequences submitted as Fot1 transposons from $F$. oxysporum f. sp. ciceris (unpublished sequence AY039816), $F$. oxysporum (10), and $F$. solani var. minus (8). In the Fusarium comparative genome database, there were 36 different regions with similarity to the IRAPOne sequence that were located on 15 different supercontigs of the $F$. oxysporum f. sp. lycopersici genome. The longest of these sequence matches consisted of a 465-bp region, whereas 22 of the matches were $<104 \mathrm{bp}$ in length. Only $117 \mathrm{bp}$ (positions 1 to 21 and 319 to $415 \mathrm{bp}$ ) in the IRAP-One sequence had no similarity to sequences in any of the two sequence databases (Table 3). These regions were selected for designing SCAR primers.

The IRAP-Two sequence (783 bp) had no matches in GenBank (BLASTN and BLASTX) but many (169 regions distributed across 19 supercontigs) in the $F$. oxysporum f. sp. lycopersici genome database. Most $(n=156)$ of these matches were $<100 \mathrm{bp}$ in length, whereas the longest match consisted of a 227-bp region.
The sequence did, however, contain a 261-bp region (positions 337 to 498 ) for which no similarity was found in the $F$. oxysporum databases. This region was used for designing SCAR primers (Table 3 ).

Regions within the OPA-05 sequence (402 bp) had similarity in GenBank and the Fusarium genome database. In GenBank, the OPA-05 3' region (base pairs 239 to 400) had 92\% (151/165) sequence similarity to the $18 \mathrm{~S}$ rDNA gene of several ascomycete fungi (Table 3). In the Fusarium genome database, this same region also had similarity to several supercontigs in the $F$. oxysporum f. sp. lycopersici, $F$. verticillioides, and $F$. graminearum genomes. SCAR primers designed for the OPA-05 region targeted the region (1 to $251 \mathrm{bp}$ ) for which no matches in sequence databases were found (Table 3 ).

Design and evaluation of SCAR primers. None of the OPI-18 and OPA-05 SCAR primer pair combinations, when evaluated on a small subset of the isolates, could be optimized to detect all the F. oxysporum f. sp. cepae isolates of interest without detection of some of the nonpathogenic isolates. Therefore, these SCAR primers were not evaluated further.

Evaluation of the IR-SCAR primer pair combinations on the 82 $F$. oxysporum isolates showed that only three of the primer pair combinations amplified the relevant fragments from VCG 0421, VCG 0425, and SMV 4 isolates but not from any other isolates. These IR-SCAR primer pair combinations consisted of primer pair (i) HanO-1F and HanO-2R designed from the IRAP-One sequence, (ii) Hansec- $1 \mathrm{~F}$ and Hansec-2R designed from the IRAP-Two sequence, and (iii) $\mathrm{HTH}-1 \mathrm{~F}$ and $\mathrm{HTH}-2 \mathrm{R}$ designed from the IRAP-Three sequence.

Development of IR-SCAR multiplex PCRs. Amplification with the IR-SCAR multiplex reaction (primers Hansec-1F, Hansec-2R, HTH-1F, and HTH-2R) yielded the expected 392- and 244-bp fragments for the isolates of interest, and this multiplex reaction was used to screen all $82 \mathrm{~F}$. oxysporum isolates. Amplification of this set of isolates showed that the IR-SCAR multiplex reaction was able to successfully identify isolates of the two major VCGs (0421 and 0425) as well as SMV 4. No amplification was obtained for isolates in the other VCGs and SMVs and for the nonpathogenic isolates. However, a 392-bp band was amplified from the two F. oxysporum f. sp. melonis isolates (Fig. 3).

Isolation, identification and pathogenicity testing of $F$. oxysporum isolates from onion bulbs in South Africa. In total,

TABLE 3. Similarity of Fusarium oxysporum f. sp. cepae random amplified polymorphic DNA (RAPD) and inter-retrotransposon amplified polymorphism (IRAP) polymerase chain reaction (PCR) fragments to sequences in GenBank and the Fusarium comparative genome project

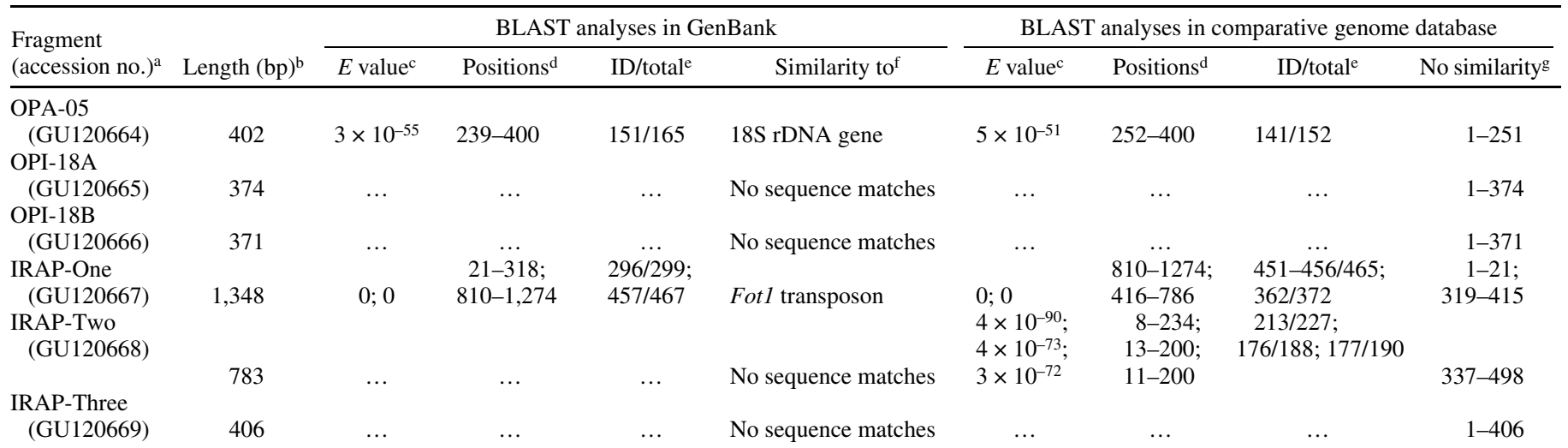

a Fragment (GenBank accession number). OPA-05 and OPI-18 refer to PCR fragments from RAPD amplifications, whereas IRAP-One, IRAP-Two, and IRAP-

Three refer to fragments from IRAP PCR amplifications.

${ }^{\mathrm{b}}$ Length of cloned fragment.

${ }^{c}$ Only those sequence matches that had the highest $E$ values are shown. Except for the OPA-05 sequence, all sequences had similarity to the $F$. oxysporum f. sp. lycopersici genome only.

${ }^{\mathrm{d}}$ Nucleotide positions in the $F$. oxysporum f. sp. cepae sequence to which similarity was found in the specific database.

${ }^{\text {e }}$ Number identities/total number of base pair matches.

f Similarity to known genes.

g Nucleotide positions in the $F$. oxysporum f. sp. cepae sequence to which no similarity was found in any of the databases. 
88 F. oxysporum isolates were obtained from onion bulbs. Pathogenicity testing showed that 65 of the isolates (STE-U 6847 to 6911 and 6929) were highly virulent $F$. oxysporum f. sp. cepae isolates, because they caused $>70 \%$ basal plate necrosis when inoculated on onion 'Coastal Cream'. The remaining 23 isolates (STE-U 6912 to 6934) were designated as $F$. oxysporum isolates nonpathogenic toward onion.

RAPD and IRAP-PCR fingerprinting of the new collection of $\boldsymbol{F}$. oxysporum isolates from onion in South Africa. RAPD fingerprinting of the new collection of $F$. oxysporum isolates (65 $F$. oxysporum f. sp. cepae and 23 nonpathogenic $F$. oxysporum) from onion bulbs showed that 62 of the $F$. oxysporum f. sp. cepae isolates contained the diagnostic OPA- 05 fragment of \pm 400 -bp and OPI-18 fragment of \pm 370 -bp that were previously identified as being associated with VCG 0425 . Thus, these $62 \mathrm{~F}$. oxysporum f. sp. cepae isolates belong to the South African VCG 0425. IRAP-PCR fingerprinting showed that the $62 F$. oxysporum f. sp. cepae isolates also contained the three IRAP-PCR fragment sizes ( $\pm 1.35 \mathrm{~kb}, \pm 780 \mathrm{bp}$, and $\pm 400 \mathrm{bp}$ ) that were previously shown to be diagnostic for VCGs 0421 and 0425 . The remaining three $F$. oxysporum f. sp. cepae isolates (STE-U 6888, 6889, and 6929) and 23 nonpathogenic $F$. oxysporum isolates did not contain any of the five aforementioned diagnostic fragment sizes. Therefore, these $F$. oxysporum f. sp. cepae isolates (STE-U 6888, 6889, and 6929) did not belong to VCG 0425. The RAPD and IRAP fingerprints of two of the three $F$. oxysporum f. sp. cepae isolates (STE-U 6888 and 6929) did not match any of the known VCGs or SMVs. The RAPD and IRAP fingerprints of the third $F$. oxysporum f. sp. cepae isolate (STE-U 6889) corresponded to that of a known SMV, SMV 3 (Figs. 1 and 2).

Validation of the IR-SCAR multiplex PCR. Evaluation of the IR-SCAR multiplex reaction (primers Hansec-1F, Hansec-2R,
HTH-1F, and HTH-2R) on a larger collection of 104 Fusarium isolates (Table 1, groups 4 and 5) showed that the multiplex reaction was specific, and that it only detected the group of $F$. oxysporum f. sp. cepae isolates which contained the five diagnostic LTR and RAPD fragments. Thus, the IR-SCAR multiplex PCR confirmed that VCG 0425 was the dominant $F$. oxysporum $\mathrm{f}$. sp. cepae VCG in South Africa.

Vegetative compatibility tests. Vegetative compatibility testing of the 14 isolates from the new collection of $F$. oxysporum isolates confirmed that $F$. oxysporum f. sp. cepae isolates STE-U $6847,6873,6880$, and 6862 belong to VCG 0425, whereas the nonpathogenic isolates STE-U 6915, 6922, 6918, 6912, 6916, and 6915 did not belong to VCG 0425 or any of the other known VCGs or SMVs. The nit mutants of $F$. oxysporum f. sp. cepae isolate STE-U 6889, for which fingerprinting data suggested that it belongs to SMV 3, formed a stable heterokaryon with the tester set of the SMV 3 reference isolate (STE-U 6658) (40). Because both these $F$. oxysporum f. sp. cepae isolates belong to the same VCG, SMV 3 can no longer be considered as a single-member VCG, and is redescribed here as VCG 0427. The two F. oxysporum f. sp. cepae isolates (STE-U 6888 and 6929) that were not identified as VCG 0425 isolates using fingerprinting and SCAR analyses also did not form stable heterokaryons with the three VCG 0425 tester strains, or with any of the other known VCGs or SMVs. Therefore, isolates STE-U 6929 and 6888 are described here as SMV 5 and SMV 6, respectively.

\section{DISCUSSION}

The current study developed a multiplex IR-SCAR PCR test for the rapid identification of the main $F$. oxysporum $\mathrm{f}$. sp. cepae VCGs (VCGs 0421 and 0425) and SMV 4 isolates in South

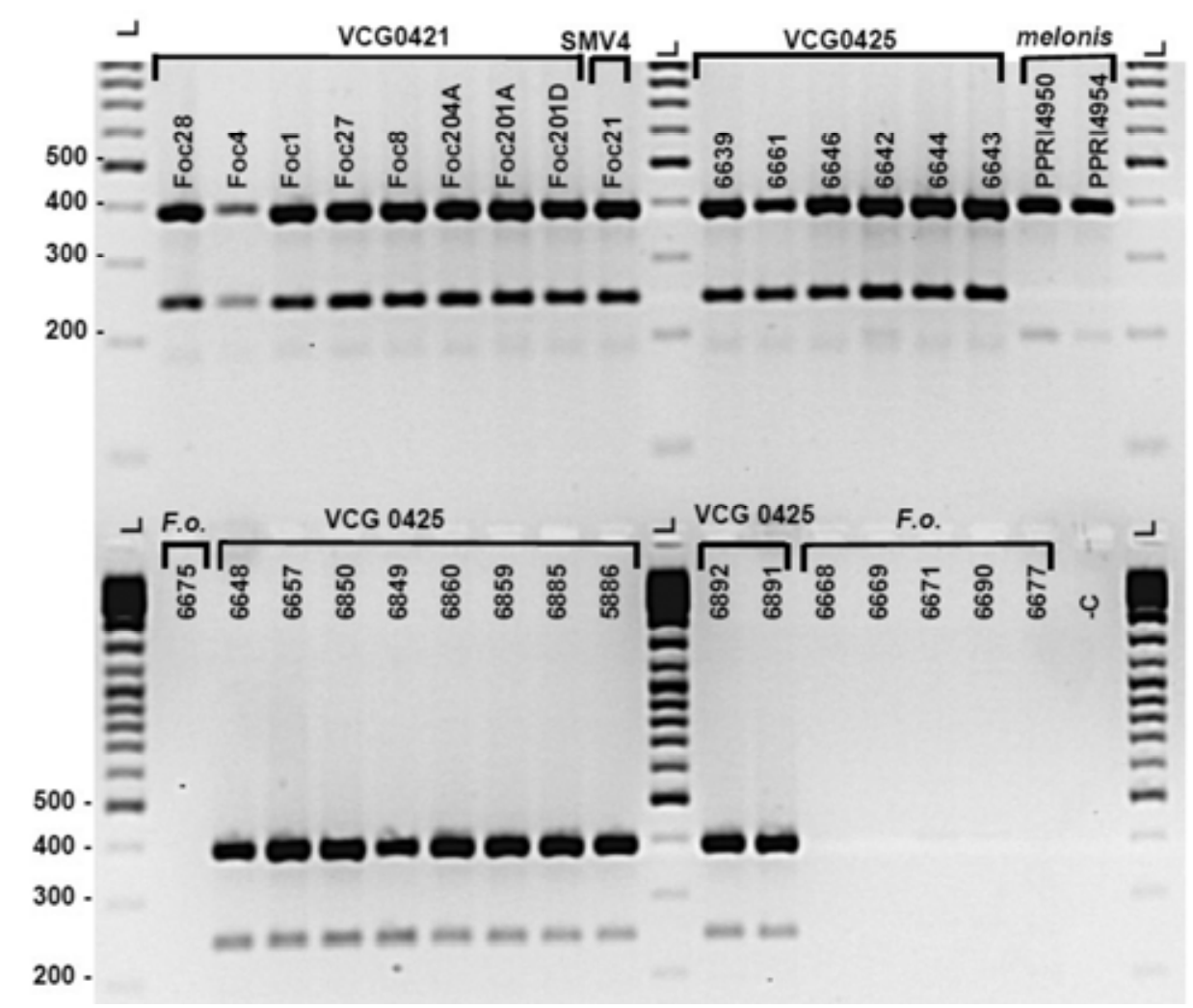

Fig. 3. Polymerase chain reaction amplification products of Fusarium oxysporum isolates amplified with inter-retrotransposon sequence-characterized amplified region (IR-SCAR) primers in multiplex reactions containing primers Hansec-1F, Hansec-2R, HTH-1F, and HTH-2R. Codes for F. oxysporum f. sp. cepae isolates from Colorado start with "Foc", whereas the South African pathogenic and nonpathogenic (F. oxysporum) isolates are indicated by numbers that are their STE-U culture collection codes. F. oxysporum f. sp. cepae VCGs = vegetative compatibility groups and SMVs = single-member VCGs. A negative water control (-C) was included in amplifications, as well as two F. oxysporum f. sp. melonis (melonis) isolates. Size fragments (bp) of a 100-bp Generuler ladder (L) are indicated on the left side of the figure. 
Africa and Colorado. The multiplex IR-SCAR PCR test identifies these isolates as a group and does not differentiate between them. Therefore, two diagnostic RAPD fragments $( \pm 400$ - and \pm 370 -bp fragments from primers OPA-05 and OPI-18, respectively) must be used to subsequently differentiate VCG 0425 isolates from VCG 0421 and the SMV 4 isolates. Using this approach, 65 previously uncharacterized $F$. oxysporum f. sp. cepae isolates from onion in South Africa were genotyped, which showed that 62 isolates belonged to VCG 0425 . This confirmed VCG 0245 as the dominant VCG causing onion basal rot in South Africa (40). Two of the $F$. oxysporum f. sp. cepae isolates each belonged to new SMVs, designated SMV 5 and 6, while the third isolate (STE-U 6889) was reclassified together with SMV 3 as a member of the newly described VCG 0427 (40). Our results indicate, therefore, that these molecular fingerprints can be used to replace the very slow technique of VCG analysis.

$F$. oxysporum f. sp. cepae VCG-associated SCAR markers could be developed from all the IRAP fragments but not from any of the RAPD fragments. This is most likely due to the fact that RAPD fragments can comprise DNA fragments of the same size that differ in sequence. We attempted to address this problem by using 3\% agarose gels and by cloning the fragments from four different VCG 0425 isolates; however, these measures were not enough. In future studies, it would be better to adopt an extremely cautionary approach that would ensure the selection of the correct cloned fragment, as was advocated by Jimenez-Gasco and Jimenez-Diaz (20). Their study selected 30 to 50 clones for each targeted fragment, which were then enzyme restriction digested, followed by the hybridization of the clones that had unique enzyme restriction patterns to blotted RAPD fragments (20). Although we could not develop our RAPD fingerprints into SCAR markers, the RAPD fingerprinting is crucial for differentiating VCG 0425 from VCG 0421 and SMV 4, and might be useful to other researchers, providing that the appropriate reference isolates are included in the PCR step and the electrophoresis step.

Our success in developing $F$. oxysporum f. sp. cepae VCGSCAR markers using the IRAP-PCR fingerprinting method could be (i) related to the fact that this is a more sequence biased method (34) and (ii) due to the IRAP method targeting regions where transposable elements have been inserted. Transposable elements have been suggested as important in the evolution and virulence of formae speciales in $F$. oxysporum $(8,9,18,44)$. Some evidence for this is the successful development of several transposon-based markers, mostly from RAPD fingerprints, for the identification of $F$. oxysporum formae speciales and races $(5,12,30,34,36)$. The importance of transposable elements in virulence in $F$. oxysporum was also suggested by Van der Does et al. (44). They showed that the putative dispensable genomic region associated with "secreted in xylem" (SIX) virulence genes in F. oxysporum f. sp. lycopersici was rich in transposable elements. More recently, Ma et al. (32) showed that $F$. oxysporum $\mathrm{f}$. sp. lycopersici contains lineage-specific regions that include four entire chromosomes, which are enriched in transposons. Two of these chromosomes, when transferred to a nonpathogenic $F$. oxysporum isolate, were able to convert the isolate into a pathogen (32). Therefore, it is possible that the $F$. oxysporum f. sp. cepae pathogenicity or virulence-associated IRAP fragments from our study may be useful tools for investigating (i) genomic regions possibly involved in virulence and pathogenicity in $F$. oxysporum f. sp. cepae and (ii) the evolution of VCGs, pathogenicity, or virulence in $F$. oxysporum f. sp. cepae. For example, JimenezGasco et al. (21) used RFLP genotyping of genomic DNA with transposable element probes, which were developed from RAPDSCAR markers (20), to formulate important hypotheses on the evolution of races within $F$. oxysporum f. sp. ciceris.

In South Africa, the IR-SCAR test will be useful, because it detects the majority ( $89 \%$ ) of $F$. oxysporum f. sp. cepae isolates causing onion bulb rot, and it may also detect the pathogen on seed and seedlings. The IR-SCAR test will also be of some use in Colorado, because it detects a relatively large number $(47 \%)$ of $F$. oxysporum f. sp. cepae isolates. In Australia and California, the IR-SCAR test may also be useful because translation EF sequences analyses showed that these isolates belong to the same clonal lineage as VCG 0421 and VCG 0425 isolates $(15,40)$ but this will require further investigation. However, in countries such as Turkey, where each $F$. oxysporum $\mathrm{f}$. sp. cepae isolate belongs to a single VCG and VCG 0421 does not occur (3), the IR-SCAR test is unlikely to be useful for identifying $F$. oxysporum f. sp. cepae isolates.

The dominance of VCG 0425 among isolates obtained from mature bulbs in South Africa was confirmed using our RAPD and IR-SCAR multiplex PCR tests. Although these PCR techniques can identify the current main VCGs in South Africa and Colorado, the dominance of these VCGs and their importance may change in future if new, ecologically fitter and more virulent VCGs emerge. Therefore, the development of a PCR test that targets known host-specific virulence genes would be a better option for identifying inoculum sources, because it is more likely to detect all isolates of the pathogen, as has been found for $F$. oxysporum f. sp. lycopersici $(29,30)$. As yet, F. oxysporum f. sp. lycopersici is the only forma specialis for which diagnostic tests have been developed that target the host-specific SIX virulence genes $(29,30)$, whereas the genetic basis of pathogenicity and virulence for $F$. oxysporum f. sp. cepae and most other $F$. oxysporum formae speciales is unknown. In $F$. oxysporum $\mathrm{f}$. sp. cepae, the chromosome on which the IRAP-Three sequence is located may be of specific interest, because no sequences in GenBank or the Fusarium comparative genome project databases matched this sequence.

\section{ACKNOWLEDGMENTS}

This research was financially supported by the European Union's Pesticide Initiative Programme for South Africa, the Koue Bokkeveld Potatoes and Onions Committee (KORKOM), Hygrotech Seed (Pty) Ltd., and Stellenbosch University. We thank S. Langenhoven, A. Pretorius, L. Mostert, and L. van der Walt for technical assistance with the research; $\mathrm{H}$. F. Schwartz (Department of Bioagricultural Sciences and Pest Management, Colorado State University, Fort Collins) for kindly providing $F$. oxysporum f. sp. cepae isolates from Colorado; and G. Fourie (Department of Microbiology and Plant Pathology, University of Pretoria, South Africa) and S. Lamprecht (Agricultural Research Council, Plant Protection Research Institute, Stellenbosch, South Africa) for providing several Fusarium reference isolates.

\section{LITERATURE CITED}

1. Alves-Santos, F. M., Ramos, B., Asunción Garciá-Sánchez, M., Eslava, A. P., and Díaz-Mínguez, J. M. 2002. A DNA-based procedure for in planta detection of Fusarium oxysporum f. sp. phaseoli. Phytopathology 92:237244.

2. Baayen, R. P., O’Donnell, K., Bonants, P. J. M., Cigelnik, E., Kroon, L. P. N. M., Roebroeck, E. J. A., and Waalwijk, C. 2000. Gene genealogies and AFLP analyses in the Fusarium oxysporum complex identify monophyletic and nonmonophyletic formae speciales causing wilt and rot disease. Phytopathology 90:891-900.

3. Bayraktar, H., Turkkan, M., and Dolar, F. S. 2010. Characterization of Fusarium oxysporum f. sp. cepae from onion in Turkey based on vegetative compatibility and rDNA RFLP analysis. J. Phytopathol. 158:691-697.

4. Bentley, S., Pegg, K. G., and Dale, J. L. 1994. Optimization of RAPD PCR fingerprinting to analyze genetic variation within populations of Fusarium oxysporum f. sp. cubense. Phytopathology 142:64-78.

5. Chiocchetti, A., Bernardo, I., Daboussi, M.-J., Garibaldi, A., Gullino, M. L., Langin, T., and Migheli, Q. 1999. Detection of Fusarium oxysporum $\mathrm{f}$. sp. dianthi in carnation tissue by PCR amplification of transposon insertions. Phytopathology 89:1169-1175.

6. Chiocchetti, A., Sciaudone, L., Durando, F., Garibaldi, A., and Migheli, Q. 2001. PCR detection of Fusarium oxysporum f. sp. basilici on basil. Plant Dis. 85:607-611. 
7. Clark, C. A., Hyun, J.-W., and Hoy, M. W. 1998. Relationships among wilt-inducing isolates of Fusarium oxysporum from sweet potato and tobacco. Plant Dis. 82:530-536.

8. Daboussi, M.-J., Daviere, J. M., Graziana, S., and Langin, T. 2002. Evolution of the Fotl transposon in the genus Fusarium: Discontinuous distribution and epigenetic inactivation. Mol. Biol. Evol. 19:510-520.

9. Daboussi, M.-J., and Langin, T. 1994. Transposable elements in the fungal plant pathogen Fusarium oxysporum. Genetics 93:49-59.

10. Daboussi, M.-J., Langin, T., and Brygoo, Y. 1992. Fot1, a new family of fungal transposable elements. Mol. Gen. Genet. 232:12-16.

11. De Haan, L. A. M., Numansen, A., Roebroeck, E. J. A., and Van Doorn, J. 2000. PCR detection of Fusarium oxysporum f. sp. gladioli race 1, causal agent of Gladiolus yellows disease, from infected corms. Plant Pathol. 49:89-100.

12. Fernandez, D., Quinten, M., Tanaoui, A., Geiger, J. P., and Langin, T. 1998. Fot 1 insertions in the Fusarium oxysporum f. sp. albedinis genome provide diagnostic PCR target for detection of the date palm pathogen. Appl. Environ. Microbiol. 64:633-636.

13. Fourie, G., Steenkamp, E. T., Gordon, T. R., and Viljoen, A. 2009. Evolutionary relationships among the Fusarium oxysporum f. sp. cubense vegetative compatibility groups. Appl. Environ. Microbiol. 75:4770-4781.

14. Freeman, S., and Maymon, M. 2000. Reliable detection of the fungal pathogen Fusarium oxysporum f. sp. albedinis, causal agent of Bayoud disease of date palm, using molecular techniques. Phytoparasitica 28:341348.

15. Galván, G. A., Koning-Boucoiran, C. F. S., Koopman, W. J. M., BurgerMeijer, K., González, P. H., Waalwijk, C., Kik, C., and. Scholten, O. E. 2008. Genetic variation among Fusarium isolates from onion, and resistance to Fusarium basal rot in related Allium species. Eur. J. Plant Pathol. 121:499-512.

16. Grajal-Martin, M. J., Simon, C. J., and Muehlbauer, F. J. 1993. Use of random amplified polymorphic DNA (RAPD) to characterize race 2 of Fusarium oxysporum f. sp. pisi. Mol. Plant Pathol. 83:612-615.

17. Groenewald, S., Van den Berg, N., Marasas, W. F. O., and Viljoen, A. 2006. The application of high-throughput amplified fragment length polymorphisms in assessing genetic diversity in Fusarium oxysporum $\mathrm{f}$. sp. cubense. Mycol. Res. 110:297-305.

18. Hua-Van, A., Daviere, J. M., Kaper, F., Langin, T., and Daboussi, M.-J. 2000. Genome organization in Fusarium oxysporum: Clusters of class II transposons. Curr. Genet. 37:339-347.

19. Hua-Van, A., Langin, T., and Daboussi, M.-J. 2001. Evolutionary history of the impala transposon in Fusarium oxysporum. Mol. Biol. Evol. 18:1959-1969.

20. Jimenéz-Gasco, M. M., and Jiménez-Díaz, R. M. 2003. Development of a specific polymerase chain reaction-based assay for the identification of Fusarium oxysporum f. sp. ciceris and its pathogenic races $0,1 \mathrm{~A}$, and 6 . Phytopathology 93:200-209.

21. Jiménez-Gasco, M. M., Milgroom, M. G., and Jiménez-Díaz, R. M. 2004. Stepwise evolution of races in Fusarium oxysporum f. sp. ciceris inferred from fingerprinting with repetitive DNA sequences. Phytopathology 94:228-235.

22. Jiménez-Gasco, M. M, Pérez-Artés, E., and Jiménez-Díaz, R. M. 2001. Identification of pathogenic races $0,1 \mathrm{~B} / \mathrm{C}, 5$, and 6 of Fusarium oxysporum $\mathrm{f}$. sp. ciceris with random amplified polymorphic DNA (RAPD). Eur. J. Plant Pathol. 107:237-248.

23. Jones, C. J., Edwards, K. J., Castaglione, S., Winfield, M. O., Sala, F., Van de Wiel, C., Bredemeijer, G., Vosman, B., Matthes, M., Daly, A., Brettschneider, R., Bettini, P., Buiatti, M., Maestri, E., Malcevschi, A., Marmiroli, N., Aert, R., Volckaert, G., Rueda, J., Linacero, R., Vazquez, A., and Karp, A. 1997. Reproducibility testing of RAPD, AFLP and SSR markers in plants by a network of European laboratories. Mol. Breed. 3:381-390.

24. Kalc Wright, G. F., Guest, D. I., Wimalajeewa, D. L. S., and Van Heeswijck, R. 1996. Characterisation of Fusarium oxysporum isolated from carnation in Australia based on pathogenicity, vegetative compatibility and random amplified polymorphic DNA (RAPD) assay. Eur. J. Plant Pathol. 102:451-457.

25. Kelly, A., Alcalá-Jiménez, A. R., Bainbridge, B. W., Heale, J. B., PérezArtés, E., and Jiménez-Díaz, R. M. 1994. Use of genetic fingerprinting and random amplified polymorphic DNA to characterize pathotypes of Fusarium oxysporum f. sp. ciceris infecting chickpeas. Phytopathology 84:1293-1298.

26. Kistler, H. C. 1997. Genetic diversity in the plant-pathogenic fungus Fusarium oxysporum. Phytopathology 87:474-479.

27. Leslie, J. F., and Summerell, B. A. 2006. The Fusarium Laboratory Manual. Blackwell Publishers, IA

28. Lievens, B., Claes, L., Vakalounakis, D. J., Vanachter, A. C. R. C., and
Thomma, B. P. H. J. 2007. A robust identification and detection assay to discriminate the cucumber pathogens Fusarium oxysporum f. sp. cucumerinum and f. sp. radicis-cucumerinum. Environ. Microbiol. 9:21452161.

29. Lievens, B., Houterman, P. M., and Rep, P. 2009. Effector gene screening allows unambiguous identification of Fusarium oxysporum f. sp. lycopersici races and discrimination from other formae speciales. FEMS Microbiol. Lett. 300:201-215.

30. Lievens, B., Rep, M., and Thomma, B. P. H. J. 2008. Recent developments in the molecular discrimination of formae speciales of Fusarium oxysporum. Pest Manage. Sci. 64:781-788.

31. Lori, G., Edel-Hermann, V., Gautheron, N., and Alabouvette, C. 2004. Genetic diversity of pathogenic and nonpathogenic populations of Fusarium oxysporum isolates from carnation fields in Argentina. Phytopathology 94:661-668.

32. Ma, L.-J., van der Does, H. C., Borkovich, K. A., Coleman, J. J, Daboussi, M.-J., Di Pietro, A., Dufresne, M., Freitag, M., Grabherr, M., Henrissat, B., Houterman, P. M., Kang, S., Shim, W.-B., Woloshuk, C., Xie, X., Xu, J.-R., Antoniw, J., Baker, S. E., Bluhm, B. H., Breakspear, A., Brown, D. W., Butchko, R. A. E., Chapman, S., Coulson, R., Coutinho, P. M., Danchin, E. G. J., Diener, A., Gale, L. R., Gardiner, D. M., Goff, S., Hammond-Kosack, K. E., Hilburn, K., Hua-Van, A., Jonkers, W., Kazan, K., Kodira, C. D., Koehrsen, M., Kumar, L., Lee, Y.-H., Li, L., Manners, J. M., Miranda-Saavedra, D., Mukherjee, M., Park, G., Park, J., Park, S.-Y., Proctor, R. H., Regev, A., Ruiz-Roldan, M. C., Sain, D., Sakthikumar, S., Sykes, S., Schwartz, D. C., Turgeon, B. G., Wapinski, I., Yoder, O., Young, S., Zeng, Q., Zhou, S., Galagan, J., Cuomol, C. A., Kistler, H. C., and Rep, M. 2010. Comparative genomics reveals mobile pathogenicity chromosomes in Fusarium. Nature 464:367-373.

33. Manulis, S., Kogan, N., Reuven, M., and Ben-Yephet, Y. 1994. Use of the RAPD technique for identification of Fusarium oxysporum f. sp. dianthi from carnation. Phytopathology 84:98-101.

34. Mes, J. J., Haring, M. A., and Cornelissen, B. J. 2000. Foxy: An active family of short interspersed nuclear elements from Fusarium oxysporum. Mol. Gen. Genet. 263:271-280.

35. Pasquali, M., Dematheis, F., Gullino, M. L., and Garibaldi, A. 2007. Identification of Race 1 of Fusarium oxysporum f. sp. lactucae on lettuce by inter-retrotransposon sequence-characterized amplification region technique. Phytopathology 97:987-996.

36. Pasquali, M., Marena, L., Fiori, R., Piatti, P., Gullino, M. L., and Garibaldi, A. 2004. Real-time polymerase chain reaction for identification of a highly pathogenic group of Fusarium oxysporum f. sp. chrysanthemi on Argyranthemum frutescens L. J. Plant Pathol. 86:55-61.

37. Puhalla, J. E. 1985. Classification of strains of Fusarium oxysporum on the basis of vegetative compatibility. Can. J. Bot. 63:179-183.

38. Roncero, M. I. G., Hera, C., Ruiz-Rubio, M., Maceira, G., Madrid, M. P., Caracuel, Z., Calero, F., Delgado-Jarana, J., Roldán-Rodríguez, R., Martéynez-Rocha, A. L., Velasco, C., Roa, J., Martín-Urdiroz, M., Cordoba, D., and Di Pietro, A. 2002. Fusarium as a model for studying virulence in soilborne plant pathogens. Physiol. Mol. Plant Pathol. 62:8798.

39. Sambrook, J., Firtsch, E. F., and Maniatis, T. 1989. Molecular Cloning: A Laboratory Manual. Cold Spring Harbor Laboratory Press, Cold Spring Harbor, NY.

40. Southwood, M. J. 2010. Evolution and detection of Fusarium oxysporum f. sp. cepae in onion. Ph.D. thesis, Stellenbosch University, South Africa.

41. Swift, C. E., Wickliffe, E. R., and Schwartz, H. F. 2002. Vegetative compatibility groups of Fusarium oxysporum f. sp. cepae from onion in Colorado. Plant Dis. 86:606-610.

42. Vakalounakis, D. J., Doulis, A. G., and Klironomou, E. 2005. Characterization of Fusarium oxysporum f. sp. radicis-cucumerinum attacking melon under natural conditions in Greece. Plant Pathol. 54:339-346.

43. Vakalounakis, D. J., Wang, Z., Fragkiadakis, G. A., Skaracis, G. N., and Li, D.-B. 2004. Characterization of Fusarium oxysporum isolates obtained from cucumber in China by pathogenicity, VCG, and RAPD. Plant Dis. 88:645-649.

44. Van der Does, H., Lievens, B., Claes, L., Houterman, P. M., Cornelissen, B. J. C., and Rep, M. 2008. The presence of virulence locus discriminates Fusarium oxysporum isolates causing tomato wilt from other isolates. Environ. Microbiol. 10:1475-1485.

45. Yoo, S. J., Watanabe, H., Kobayashi, K., Ogoshi, A., and Kodama, F. 1993. Vegetative compatibility grouping of formae speciales of Fusarium oxysporum pathogenic to the Liliaceae. Ann. Phytopathol. Soc. Jpn. 59:3-9.

46. Zambounis, A. G., Paplomatas, E., and Tsaftaris, A. S. 2007. Intergenic spacer-RFLP analysis and direct quantification of Australian Fusarium oxysporum f. sp. vasinfectum isolates from soil and infected cotton tissue. Plant Dis. 91:1564-1573. 